\title{
Vibratory Communication and its Relevance to Reproductive Isolation in two Sympatric Stink Bug Species (Hemiptera: Pentatomidae: Pentatominae)
}

\author{
Raul A. Laumann ${ }^{1}$ - Andrej Čokl ${ }^{2}$. \\ Maria Carolina Blassioli-Moraes ${ }^{1} \cdot$ Miguel Borges $^{1}$
}

Revised: 5 October 2016 / Accepted: 18 October $2016 /$

Published online: 29 October 2016

(C) Springer Science+Business Media New York 2016

\begin{abstract}
Communication is in phytophagous stink bugs of the subfamily Pentatominae related to mating behavior that among others includes location and recognition of the partner during calling and courting. Differences in temporal and frequency parameters of vibratory signals contributes to species reproductive isolation. Chinavia impicticornis and C. ubica are two green Neotropical stink bugs that live and mate on the same host plants. We tested the hypothesis that differences in temporal and spectral characteristics of both species vibratory signals enable their recognition to that extent that it interrupts further interspecific communication and copulation. To confirm or reject this hypothesis we monitored both species mating behaviour and recorded their vibratory songs on the non-resonant loudspeaker membranes and on the plant. The level of interspecific vibratory communication was tested also by playback experiments. Reproductive behavior and vibratory communication show similar patterns in both Chinavia species. Differences observed in temporal and spectral characteristics of female and male signals enable species discrimination by PCA analyses. Insects that respond to heterospecific vibratory signals do not step forward to behaviors leading to copulation. Results suggest that species isolation takes place in both investigated Chinavia species at an early stage of mating behavior reducing reproductive interference and the probability of heterospecific mating.
\end{abstract}

Electronic supplementary material The online version of this article (doi:10.1007/s10905-016-9585-x) contains supplementary material, which is available to authorized users.

Raul A. Laumann

raul.laumann@embrapa.br

1 Semiochemicals Laboratory, Embrapa Genetic Resources and Biotechnology, Avda W5 Norte (Final), Brasília, DF 71070-917, Brazil

2 Department of Organisms and Ecosystems, National Institute of Biology, Večna pot 111, 1000 Ljubljana, Slovenia 
Keywords Chinavia $\cdot$ mate system $\cdot$ multimodal communication $\cdot$ reproductive interference $\cdot$ pheromone $\cdot$ vibratory signals

\section{Introduction}

Communication plays a central role in animal behavior and evolution. Signals transmit information that among many tasks reduces uncertainty and modulates sexual behavior (Scott-Philips 2008; Seyfarth et al. 2010). Insects communicate with signals of different modalities transmitted in air, solids and water. Chemical and acoustic signals predominantly transmit information through the air (Greenfield 2002) and on plants most insect communicate with the substrate-borne component of their vibratory emissions (Cocroft and Rodrígues 2005). In plant-dwelling stink bugs of the subfamily Pentatominae vibratory signals are produced principally by abdomen vibration, they are related to reproductive behavior, modulating location, recognition and choice of mates and attraction and/or rivalry (Čokl 2008; Čokl et al. 2014). Vibratory signals are part of a communication repertoire that starts when males release sex pheromone to attract females to the same plant (Borges et al. 1987; Aldrich 1988; Blassioli-Moraes et al. 2008).

Prezygotic reproductive isolation among populations is one of the principal forces in patterns of speciation (Kirkpatrick and Ravigne 2002). In this context differences in courtship behavior and signals characteristics, the phenotypic architecture of behavioral isolation, among closely related species are relevant to preventing hybridization (Ryan and Rand 1993; Mendelson and Shaw 2012). Notwithstanding reproductive interference may take place when signals characteristics and/or receivers preferences of sympatric species overlap conducing to heterospecific interactions with direct or indirect fitness costs (Gröning and Hochkirch 2008).

In Pentatominae vibratory signals differences in temporal and spectral characteristics are related to the level of species specificity (Čokl and Virant-Doberlet 2003; BlassioliMoraes et al. 2005; Čokl 2008; Žunič et al. 2011). This is especially relevant to sympatric species that live, feed and mate at the same time and at the same place. To our knowledge the only investigation among Pentatominae of the reproductive barrier carried by vibratory signals among sympatric species was conducted on Nezara antennata Scott, 1874 and N. viridula (Linnaeus 1758) (Kon et al. 1988). The presence of heterospecific mating between individuals of populations in the sympatric area of the Wakayama Prefecture in Japan indicates that isolation barriers based on species specificity of vibratory, chemical, tactile and optical signals do not exclusively prevent reproductive interference at pre-copulatory levels (Kon et al. 1994). In the specific case of sympatric Nezara species, Kon et al. (1993) confirmed that hybridization is prevented by the complete post-mating barrier.

Chinavia impicticornis (Stål, 1872) and C. ubica (Rolston, 1983) are widely distributed in Brazil (Schwertner and Grazia 2007), being found in both natural and agricultural habitats on the same host-plants (Panizzi et al. 2000; Schwertner and Grazia 2007) and, like other stink bugs, frequently show aggregate spatial distribution (Higuchi 1992; Roggia 2009; Tillman et al. 2009). The high possibility of reproductive interference is based on observation that both species populations have the same spatial-temporal distribution in central Brazil and that several couples were detected along the insect life (Silva et al. 2015). 
Chemical signals (pheromones) in closely related stink bugs species have similar composition with variations in minor components or in specific blends between species (Blassioli-Moraes et al. 2008). The sex pheromone of $C$. impicticornis appears to be formed by only one component, trans-(Z)-(4S)-bisabolene epoxide (BE); on the other hand, the sex pheromone blend of $C$. ubica is composed of trans-(Z)-(4S)-BE and their isomer, cis-(Z)-(4S)-BE, in an approximately 10:90 ratio (Blassioli-Moraes et al. 2012). At long range, these differences in sex pheromone composition specifically attract females of each species (Blassioli-Moraes et al. 2012). These compounds are also components of Chinavia hilaris (Say, 1832) (McBrien et al. 2001) and Nezara viridula sex pheromone (Baker et al. 1987; Aldrich et al. 1987).

Because of the similar sex pheromone composition and ecological characteristics species specific vibratory signals could play a decisive role in reproductive isolation in both sympatric Chinavia species. Vibratory communication and the song repertoire of C. impicticornis were first described by Blassioli-Moraes et al. (2005). The aim of the presents work was to determine the role of vibratory communication signals in species isolation in closely related sympatric species $C$. impicticornis and C. ubica. To achieve this goal, we compared temporal and spectral parameters of vibratory signals of both species, recorded on non-resonating loudspeaker membrane and on plants, comparing differences and correlated them with specific behaviour during calling and courting. With playback experiments we tested the level of interspecific vibratory communication. We hypothesize that $C$. impicticornis and $C$. ubica produce vibratory signals that significantly contribute to reproductive isolation by their species specific temporal and spectral characteristics.

\section{Material and Methods}

All experiments were conducted at EMBRAPA Genetic Resources and Biotechnology (Brasília, DF, Brazil) in a sound insulated room on a shock-proof table to decrease environmental noise. Observations and recordings were conducted between 08:00 and 18:30 when most of the mating activities were detected in preliminary observations.

\section{Insects and Plants}

Adults of C. impicticornis and C. ubica originated from colonies maintained in the Semiochemicals Laboratory of Embrapa Genetic Resources and Biotechnology, Brasília, Distrito Federal, Brazil. Voucher specimens were deposited in the insect collection at Embrapa Genetic Resources and Biotechnology (Brasília, DF - Brazil). Rearing procedures followed those described by Blassioli-Moraes et al. (2012). In brief, the insects were reared in 81 transparent plastic containers and fed with a standard diet composed of green bean pods (Phaseolus vulgaris (L.), dry soybean seeds (Glycine max L), raw peanuts (Arachis hypogaea L.), sunflower seeds (Helianthus annuus L.) and water. A $15 \mathrm{~cm}^{2}$ plastic mesh ( $\left.\sim 40 \mathrm{mesh}\right)$ was placed against the inner wall of each container as an oviposition substrate and shelter for the bugs. The containers were covered with voile screen and kept at $26 \pm 1{ }^{\circ} \mathrm{C}$ temperature, $65 \pm 10 \% \mathrm{RH}$ under a $14 \mathrm{~L}: 10 \mathrm{D}$ photoperiod (light, 06:00 to 20:00 h). Food supply was renewed three times per week. Egg masses were collected daily and incubated in $9 \mathrm{~cm}$ ID plastic Petri dishes 
until hatch. After nymphs moulted into second instars, they were transferred to plastic containers and reared following the procedures described above. To prevent interactions between the sexes, males were separated from females after their imaginal moult and cuticular hardening (ca. $24 \mathrm{~h}$ after moulting). Sexually mature adults, $\geq 8 \mathrm{~d}$ after the final moult (Blassioli-Moraes et al. 2012), were used for all bioassays.

Soybean plants were grown in sterilized soil in plastic pots $20 \mathrm{~cm}$ high $\times 15 \mathrm{~cm}$ diameter and used in the V3 stage (Fehr et al. 1971). At this phenological stage the soybean plants are characterized by two unifoliate $(\sim 7 \times 7 \mathrm{~cm})$ and two trifoliate $(\sim 6 \times 8 \mathrm{~cm})$ leaves and a 15 to $25 \mathrm{~cm}$ high stem (Laumann et al. 2013).

\section{Recording Vibratory Signals}

Vibratory signals were recorded from C. impicticornis and C. ubica stinkbugs communicating either on a non-resonant substrate (loudspeaker membrane) or on the host plant. The experimental set-up for recordings on the loudspeaker membrane was similar to that described by Blassioli-Moraes et al. (2005). A couple was placed in an arena constructed on the membrane of a $10 \mathrm{~cm}$ diameter low-midrange loudspeaker $(40-6000 \mathrm{~Hz}$ frequency response, 8 ' $\Omega$ impedance; RadioShack, Taiwan). An acrylic box $(9 \mathrm{~cm}$ diameter $\times 4 \mathrm{~cm}$ high) was placed over the edge of the loudspeaker, without contacting its membrane, to prevent insects from walking away from the membrane surface. After the first emitted vibratory signal the box was removed. The vibratory signals emitted as vibrations of the loudspeaker membrane or soybean plant were recorded using a portable digital laser vibrometer (Polytec, model PDV 100, Waldbronn, Germany). The laser beam was oriented perpendicularly to the recording point from a distance of ca. $20 \mathrm{~cm}$. Recording points were located at one of the laterals of the loudspeaker membrane $(\sim 3 \mathrm{~cm}$ from the external edge $)$ or on the middle part of the plant stem $(\sim 10 \mathrm{~cm}$ above the soil). To obtain better reflection of the laser beam a small piece $\left(0.5 \mathrm{~cm}^{2}\right)$ of a reflective tape was attached to the loudspeaker membrane or the plant stem. Signals were digitised with a sound card (24-bit, 96-kHz, 100-dB signal-to-noise ratio, Sound Blaster Extigy, Creative Laboratories Inc., Milpitas, CA), and stored on a computer using the software Cool Edit Pro 2.0 (Syntrillium Software 2001 - Fort Wayne, Indiana, USA). Signal emissions were monitored with headphones during all times of insect observation.

\section{Behavioral Observations}

The same test protocol was used for experiments on the loudspeaker membrane and on the plant. Experiments on the loudspeaker membrane were conducted with 64 C. impicticornis and 54 C. ubica couples placed in the arena. The behavior and vibratory signal emissions were monitored and recorded until copulation. If insects did not start mating behavior within 20 min the couple was removed and the trial was classified as failed. Behavior and communication with vibratory signals on soybean plants, was tested with 20 pairs of each Chinavia species under the same experimental protocol as described for those performed on the loudspeaker membrane. On plants, a male and a female were placed on opposite leaves of the soybean plant and mating with vibratory communication signals was recorded until copulation. The trial was classified as a failure if the insects displayed no mating behavior within $20 \mathrm{~min}$ or if a male or a female left the plant. 


\section{Terminology and Data Analysis}

Sequences of courtship and copulation behaviors were described using behavior categories previously determined for other pentatomids (Harris and Todd 1980; Borges et al. 1987; Zahn et al. 2008) (Table 1). Pulse was defined as a unitary homogeneous parcel of vibration of finite duration, pulse trains as repeatable and temporally distinct groups of pulses and a song as a sequence of pulses and/or pulse trains with a distinct beginning and end (Figs. 2 and 3) (Broughton 1963). Signal duration was measured between its onset and its end where its amplitude reached the noise level. Repetition time was defined as the time between onsets of two sequential signals. Frequency characteristics were described by frequency spectra (fast Fourier transform (FFT) size 32,768, FFT overlap 75 \%, smoothing window BlackmanHarris and display range $60 \mathrm{~dB}$ ) and sonograms (FFT size 8192, FFT overlap $99 \%$, smoothing window Blackman-Harris display range $80 \mathrm{~dB}$ ). Frequency characteristics were described by the dominant and harmonic peaks and by frequency modulation described as downward or upward-orientated frequency sweeps. Songs were classified in the sequence of their emission (Čokl et al. 2001). All spectral and temporal characteristics were determined using the software Sound Forge 6.0 (Sonic Foundry http://www.sonicfoundry.com).

\section{Heterospecific Couples Experiments in Arenas}

To check how the different behavioral steps/vibratory communication could benefit reproductive isolation in these sympatric species, 25 heterospecific couples were

Table 1 Behavioral categories performed by Chinavia impicticornis and Chinavia ubica in a closed arena and described in the ethogram

\begin{tabular}{|c|c|}
\hline $\begin{array}{l}\text {-Behavioural } \\
\text { category code }\end{array}$ & Description of behaviour \\
\hline nrb & No reproductive behavior (insects that did not show any behavior) \\
\hline FapM & Female approaches the male \\
\hline MapF & Male approaches the female \\
\hline FS-1a or $1 b$ & First vibratory signal of female type $\mathrm{a}$ or $\mathrm{b}$ (for description see text) \\
\hline MS-1 & First vibratory signal of male (for description see text) \\
\hline MS-2 & Second vibratory signal of male (for description see text) \\
\hline An & Antennation \\
\hline FrejM & Female rejects the male \\
\hline MrejF & Male rejects the female \\
\hline $\mathrm{Mp}$ & Male pivoting, male moves in semi-circle around abdomen of female during antennation \\
\hline $\mathrm{MbF}$ & $\begin{array}{l}\text { Male beats female: Male puts head behind the female abdominal tip and beats her } \\
\text { abdomen until she adopts the copulatory position }\end{array}$ \\
\hline Fcoppos & $\begin{array}{l}\text { Female adopts copulatory position. Female elevates the tip of the abdomen and stays } \\
\text { immobile }\end{array}$ \\
\hline Mcoppos & $\begin{array}{l}\text { Male adopts copulatory position. Male goes down from the female and turns } 180^{\circ} \text {; } \\
\text { the insects are oriented end to end in copulatory position }\end{array}$ \\
\hline Copulation & Pairs copulate \\
\hline No copulation & No copulation, insects separate and walk away from one another \\
\hline
\end{tabular}


formed and evaluated under the same experimental procedures described above for conespecific couples on loudspeaker membranes.

\section{Playback Experiments}

Two types of playback experiments were conducted on the soybean plants. Stimulation programs were synthesized by Cool Edit Pro software using pre-recorded loudspeaker signals from 3 to 5 different individuals of each species. Sequences of pulses or pulses trains of each individual were mixed as required to build up each type of stimulation program. The stimulation vibrational signals were applied on the middle area of the central leaflet of a trifoliate leaf of a soybean plant by a entomological pin (Bioquip Insect Pins $\mathrm{N}^{\circ}$ 2, Bioquip, Rancho Dominguez, CA, U.S.A.) fixed to the top of a vibration exciter (Mini-shaker Type 4810, Bruel \& Kjaer, Naerum, Denmark). Horizontally positioned vibration exciter was mechanically isolated from the substrate by iron support coated with polyurethane foam.

Insects were placed individually (one male or one female of each species) on one of the opposite trifoliate leaf and stimulated with different stimulation programs. In the first experiment on the plants, males and females of each species were stimulated with four different stimulation programs that contained two types of female or male songs pre-recorded from the bugs singing on a loudspeaker membrane (see above). Each stimulation program lasted three minutes with one type of song spaced by $1 \mathrm{~min}$ of silence. The stimulation programs were played back during $20 \mathrm{~min}$, using the loop play function of the Sound Forge software. The intensity of stimulation was adjusted to the level of the insects' emissions recorded on the loudspeaker. Ten males and ten females of each species were tested with each stimulation program (conspecific and heterospecific male and female signals). Within each test behavior of insects was monitored simultaneously with recording their vibratory emissions to correlate the number of insects that responded to stimulation.

In the second experiment males were stimulated by song programs composed of two types of con- and heterospecific female songs in a sequence of $3 \mathrm{~min}$ for each species spaced with 1 min of silence. The males of each species were stimulated with four different song programs. The first started with FS-1a of C. ubica followed by FS-1a of C. impicticornis and the second by FS-1a signals pre-recorded from females in reverse species sequence. The third program started with $C$. ubica FS-1b followed by the sequence of FS-1b signals of $C$. impicticornis. The fourth program contained the latter sequences in the reverse species order with $C$. impicticornis FS-1b signals in front. Specificity of male responses was determined by the number of male responses to each stimulation test sequence together with analysis of the impact of different stimulation signals on male vibratory response characteristics. For each type of stimulation program, a total of 10 males of each species were tested. The level of response was determined by the ratio of the number of pulses emitted by the tested male to the number of playback pulses.

\section{Statistical Methods}

Data from all recorded courtship sequences were used to create a first-order Markovian behavioral transition matrix of total frequency of transitions (i.e. moving from one 
behavioral step to the next). The repetition of a single behavior (self-transition) was not included in the records to avoid the possible influence in the relative weight of transitions between behaviors. Transition probabilities were calculated from the observed frequency of a transition between two events divided by the total number of occurrences of the first event (Haccou and Meelis 1992). The expected values of the matrix cells were obtained by multiplying the total values of each column and row of the respective cell and dividing by the grand total of the matrix (total number of transitions observed) and the statistical significance of the individual transitions was evaluated by $\chi^{2}$ test with significance adjusted by Bonferroni error correction. The results are shown graphically in an ethogram.

Signal parameters (pulse train duration, pulse train repetition time, pulse duration, pulse repetition time and dominant frequency) were compared using a linear mixed model, with species as fixed effects and individuals as the random variable, to consider the repeated measures of pulses or pulses trains made in each individual. The level of significance for the fixed variance was obtained per convergence of Markov chain Monte Carlo test. To compare the number of pulses by pulse train mixed generalized linear models were used; the model considered species as fixed effects and individuals as the random variable and included Poisson error distribution. All analyses were performed in R software, version 3.0.1, using the libraries lme4, languageR and zipfR.

To analyse if FS-1 or MS pulse train signals could be differentiated between species and type (in the case of FS-1a and FS-1b) by their temporal and spectral components, principal component analyses (PCAs) were performed using the correlation matrix as input and mean values of 5 to 10 individuals of each species or signal type. MS2 signals were not included in analyses because of the irregular pattern of emission. PCA analyses were performed using the software PAST version 2.17 (Hammer et al. 2001, http://folk.uio.no/ohammer/past).

For all analyses considering temporal and spectral parameters of signals only insects that maintained each type of signal emission for more than $1 \mathrm{~min}$ and signals not superimposed with those of the partners were considered.

Mean proportion of responses of insects of each species and sex were calculated from parameters of logistic regression using signals as a factor and binomial responses (+ or -) as the response variable. Additionally, to study if the responses to heterospecific signals are similar to those observed in conspecific interactions, odds ratios (chance of response to heterospecific signal in relation to conspecific) and their confidence intervals ( $95 \%$ ) were calculated. The ratio of the number pulses emitted by each insect to the number of pulses of the played-back signals of the stimulation programs was analysed using beta regression considering species and first signal in the sequence as factors.

\section{Results}

\section{Reproductive Behavior and Vibratory Signals Emission}

In the loudspeaker arena conspecific couples of both species show stereotyped transition sequences of behavior (Fig. 1), with similar behavioral categories and transition sequences. Copulation was recorded in 52 of $64(81.25 \%)$ C. impicticornis and in 41 of $54(76 \%)$ C. ubica couples. 


\section{Chinavia impicticornis}

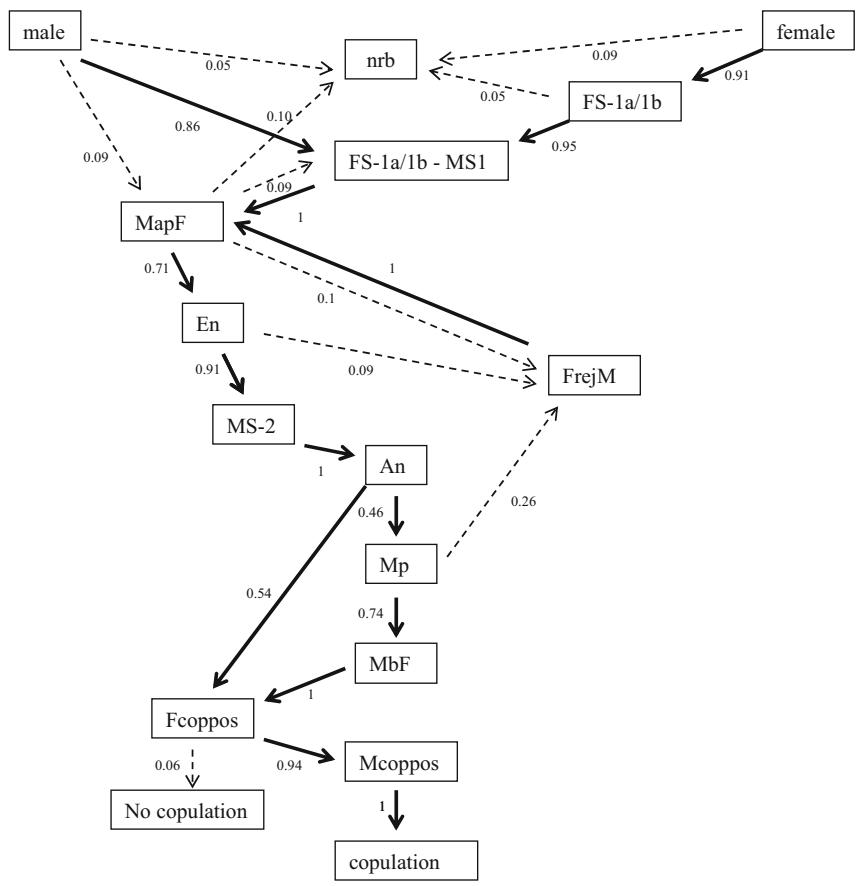

Chinavia ubica

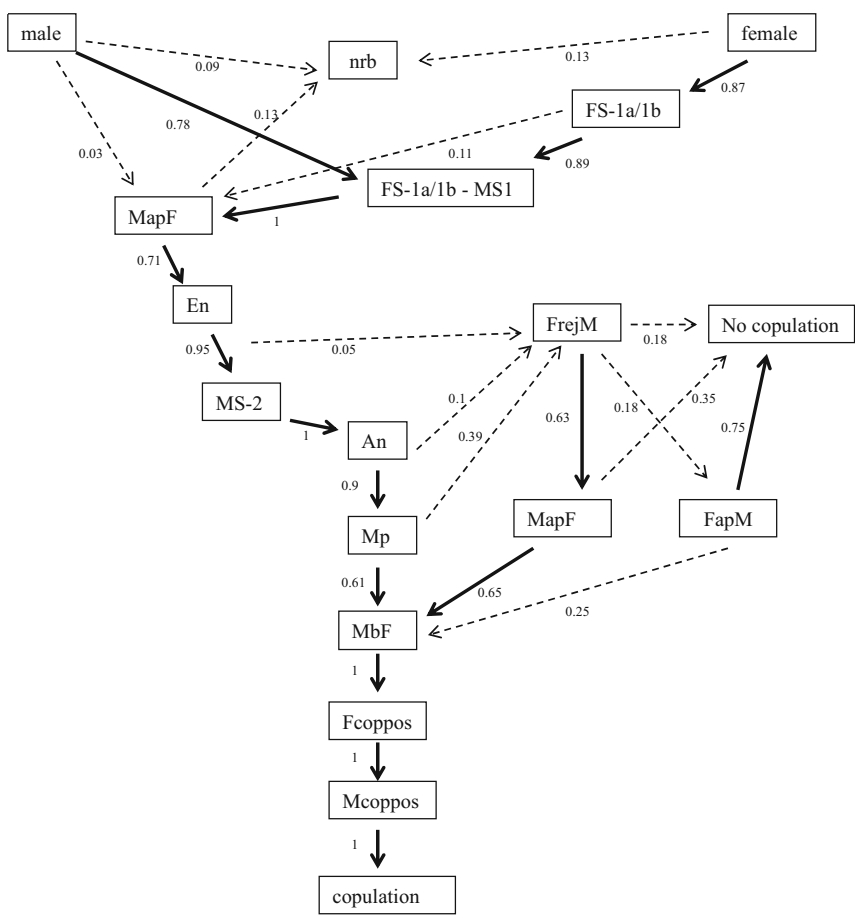


Fig. 1 Sequence of courtship and mating behavior of Chinavia impicticornis and Chinavia ubica couples. Values at left or below lines represent the probability of transitions between behaviors. Solid-line arrows indicate the significant transitions $(P<0.05)$ and dashed-line arrows the non-significant transitions $(P>0.05)$. Boxes represent behavioral categories. FS-1a = female vibratory signal $1 \mathrm{a}, \mathrm{FS}-1 \mathrm{~b}=$ female vibratory signal $1 \mathrm{~b}, \mathrm{MS}-1=$ male vibratory signal 1, MS-2 = male vibratory signal 2 . Codes for behavioral categories are listed in Table 1

One female and two different male vibratory songs were identified during different behavioral steps of mating behavior in C. impicticornis and C. ubica. The behavioral context of the song repertoire did not differ in the two species: females started vibratory communication with the female song FS-1 that triggered male response with the first song (MS-1) that silenced the female by transition to the second male song (MS-2) as typical emission leading to copulation (Fig. 1).

Most of the females observed in closed arenas initiated the reproductive sequence by spontaneous emission of FS-1 signals (91 \%, 58/64 in C. impicticornis and 87 \%, 46/54 in C. ubica). FS-1 triggered the emission of MS-1 (86\% of C. impicticornis and $78 \%$ of $C$. ubica) forming the duet that, in sequence, initiated directional movement of the male towards the female's position (Fig. 1). Antennation phase characterized by male emission of the MS-2 started when the male reached the female at the distance that enabled physical contact between mates, in many cases (40 of 52 couples $(76.92 \%)$ in C. impicticornis and 28 of $41(68.3 \%)$ in C. ubica) the emission of these signals was maintained during pivoting and kicking steps until copulation. During these steps female rejection of a male occurred in most cases (Fig. 1). If the male was not rejected mates adopted the copulatory position and copulation started. The most evident difference between species in the courtship phase of reproductive behavior was the higher tendency of $C$. impicticornis females to adopt the copulatory position directly after antennation (Fig. 1). Similar behaviors were observed in couples mating on plants.

\section{Signal Characteristics}

Signals recorded from the loudspeaker membrane or plants showed similar characteristics. We show data on the temporal and spectral parameters of signals recorded on a plant with comparative data on parameters of signals recorded on the loudspeaker membrane presented in on-line resources as electronic supplementary material (Tables ES1 and ES2).

The FS-1 of both Chinavia species is composed of readily repeated pulse trains of two types (FS-1a and FS-1b) (Fig. 2). Both types may appear in the same sequence with FS-1b usually following FS-1a. The basic pattern of both FS-1 song types does not differ between species. Highly uniform pulses, pulse train duration and repetition time are characteristics of FS-1a. This signal is composed of a sequence of pulse trains with a higher number of pulses per pulse train, longer duration and a lower repetition rate in C. impicticornis compared with C. ubica (Table 2). The dominant frequency of plant recorded FS-1a signals ranges around $100 \mathrm{~Hz}$, with lower values in C. impicticornis than in C. ubica (Table 2).

The second type of the female song (FS-1b) (Fig. 2) develops from FS-1a and shows in both species a characteristic pulse train pattern composed of a longer pulse followed by one (C. impicticornis) or from one to a few (C. ubica) short pulses, so FS-1b appears to develop from fusion of initial pulses of the FS-1a pulse train (Table 2). Similar 

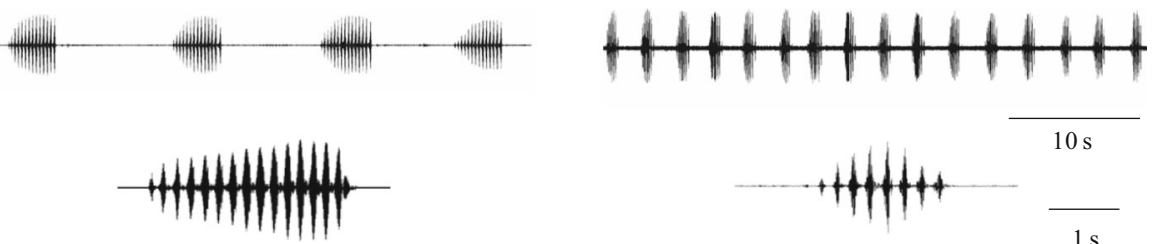

$10 \mathrm{~s}$
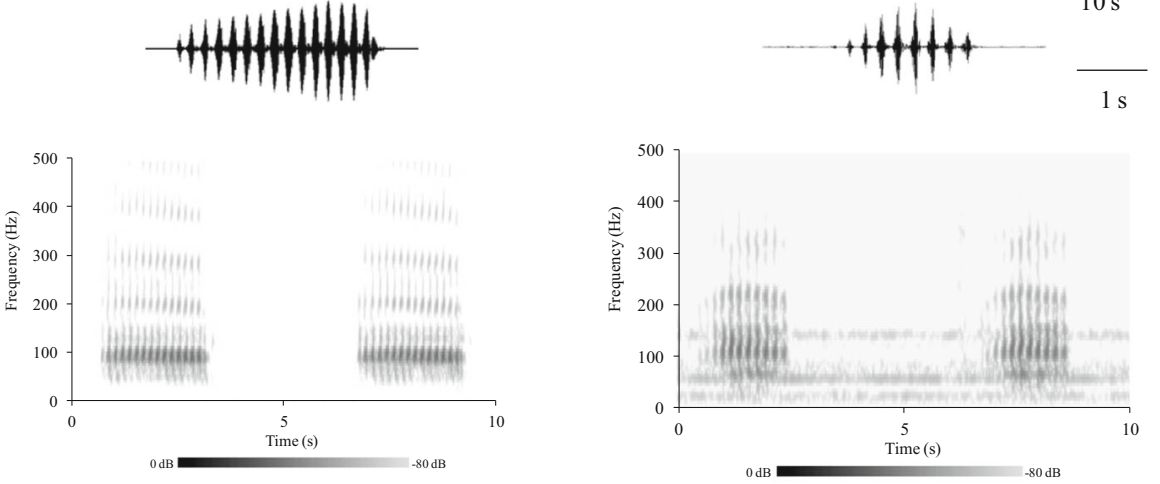

FS-1b

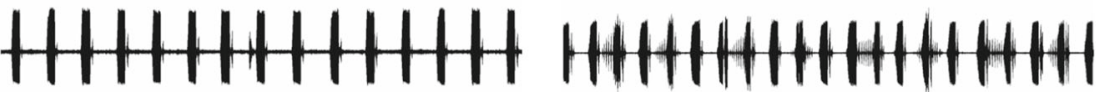
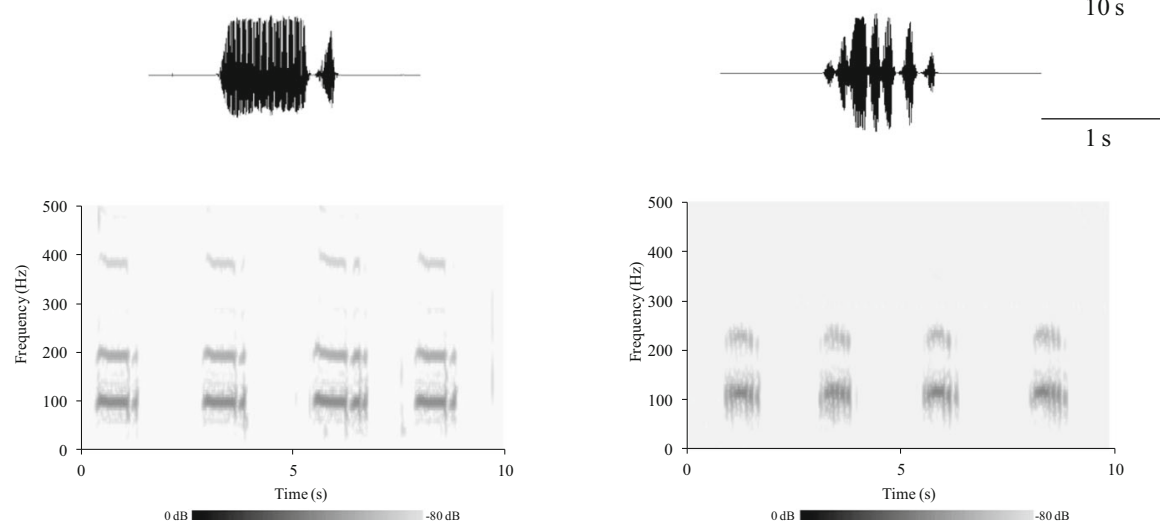

Fig. 2 Typical oscillograms and frequency spectra of Chinavia impicticornis and Chinavia ubica female songs. An oscillogram of a long sequence of pulse trains (upper), a pulse train showing in details the pulses components (middle) and a frequency spectrum of two to four consecutive pulses trains (inferior). In Chinavia ubica FS-1b it is possible to observe some pulses of MS-1 of lower amplitude

differences, as those found in FS-1a, in time parameters and dominant frequency were found when compared C. impicticornis with C. ubica FS-1b (Table 2).

Males of both species respond to FS-1a and FS-1b by the emission of the first male song (MS-1) pulse trains. In characteristic female-male duets MS-1 pulse trains alternate in a regular 1:(1-3) fashion (Fig. 3). In C. impicticornis prolonged MS-1 pulse trains may overlap the following FS-1 signal. In C. ubica duration of MS-1 pulse trains is always constrained to the interval between two FS-1 signals. In both species we have 


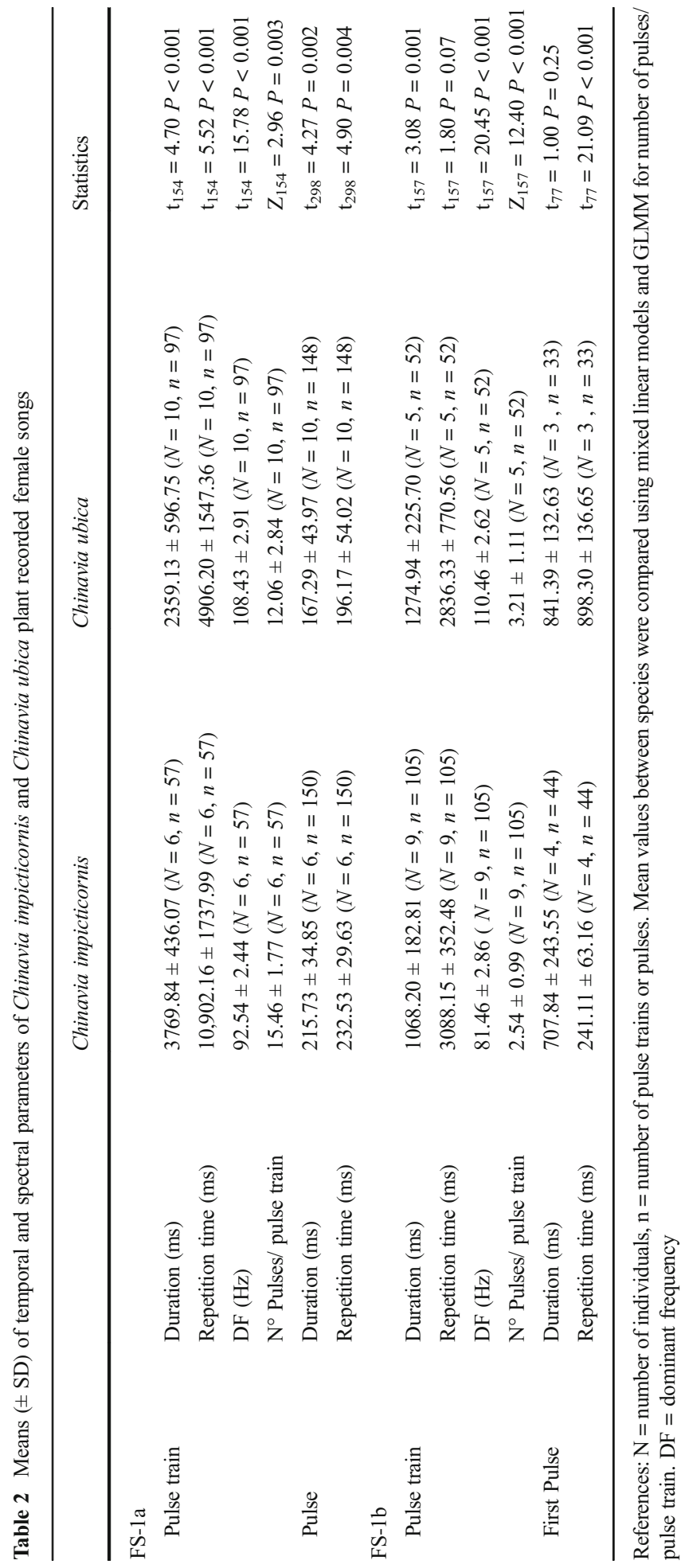


Chinavia impicticornis
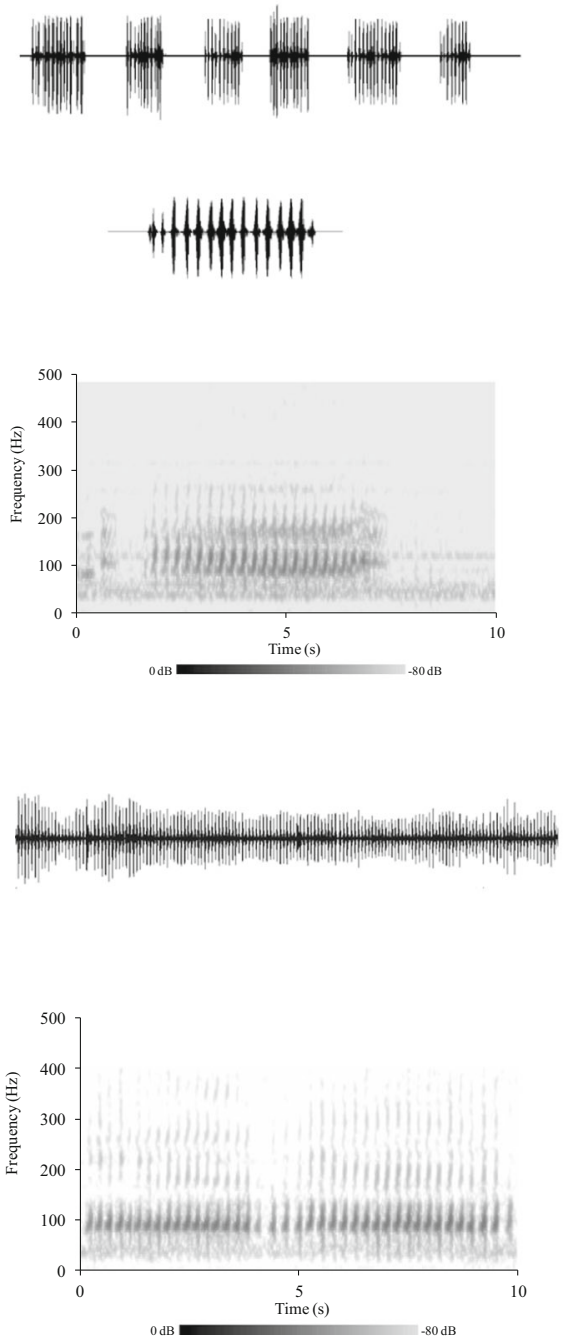

Chinavia ubica

MS-1
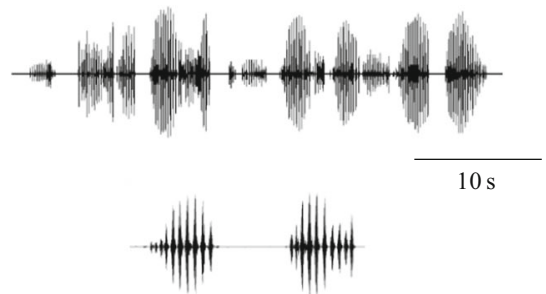

$\overline{1 \mathrm{~s}}$

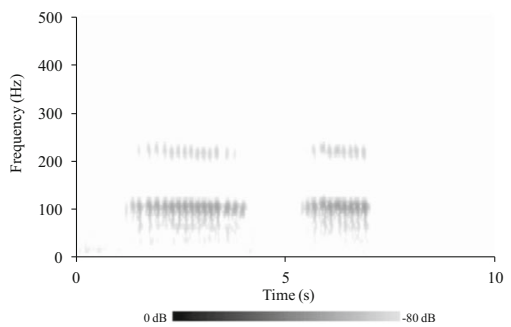

MS-2
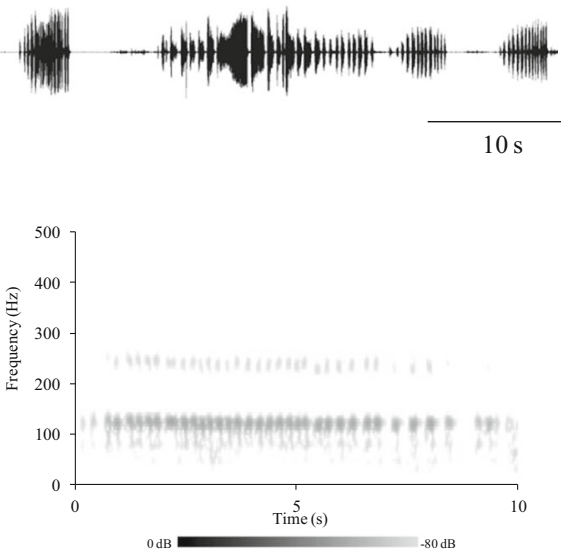

Fig. 3 Typical oscillograms and frequency spectra of Chinavia impicticornis and Chinavia ubica male songs. An oscillogram of a long sequence of pulse trains (MS-1) or pulses (MS-2) (upper), a pulse train showing in details the pulses components (midle, only for MS-1) and a frequency spectrum of one (C. impicticornis) and two consecutive pulses trains (C. ubica) and several individual pulses of MS-2 (inferior). In C. ubica MS-1 it is possible to observe some pulses of FS-1 of lower amplitude

recorded emission of MS-1 signals also after the female stopped singing and in the silent period after play-back stimulation (see playback experiments). MS-1 pulse trains of both species have a similar time pattern but differ mainly in the pulse train duration and number of pulses per pulse train (Table 3 ).

Like in FS-1 the dominant frequency of $C$. impicticornis MS-1 is lower compared with that one of C. ubica and duration and repetition time values are longer in pulses of 


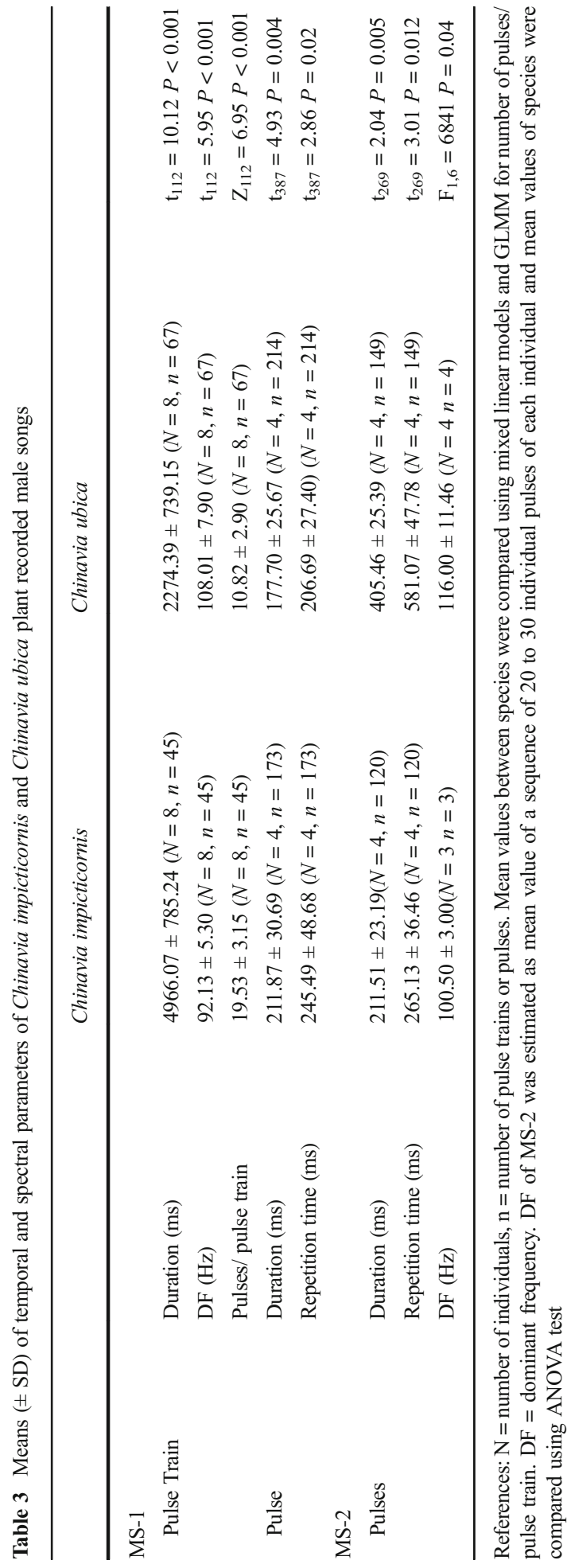


C. impicticornis compared with C. ubica (Table 3). Mainly in the pulse train duration and number of pulses per pulse train (Table 3).

Prior to copulation males change MS-1 into the MS-2 song that silences the female. The well-structured MS-1 pulse train song pattern changes in $C$. impicticornis to a minute-long sequence of readily repeated pulses of unique duration and velocity that cyclically varies along the sequence (Fig. 3, Table 3). A similar pattern is characteristic also for $C$. ubica males MS-2 pulses of that differ mainly by their longer duration, repetition time and lower velocity (Fig. 3, Table 3) that does not show regular variation as shown in C. impicticornis. The individual minimal and maximal dominant frequency values of $10 \mathrm{~s}$ long sequences were 97 and $104 \mathrm{~Hz}$ in C. impicticornis and 104 and $135 \mathrm{~Hz}$ in C. ubica.

Results of PCA analyses for FS-1 pulse train signals showed a clear separation between species and type (1a or 1b) signals. The first component of PCA that explains $66.99 \%$ of total variability was defined principally by temporal parameters of signals and the second component ( $24.86 \%$ of variability) was defined by dominant frequency (Fig. 4). These results confirm that C. ubica FS-1 signals differ from those of the sympatric $C$. impicticornis species by their temporal and spectral (dominant frequency) components and that FS-1a type differs from FS-1b by different pulse duration, repetition time and number of pulses per pulse train (Fig. 4). PCA analyses of the parameters of MS-1 pulse train signals show clear separation between individuals of both species. As for female signals, the first component of PCA that explains most of the observed variability ( $84.73 \%$ of total variability) was defined principally by temporal parameters of signals and the second component $(10.28 \%$ of variability) was defined by the dominant frequency. Differentiation between species is principally obvious in different pulse train temporal parameters being higher in C. impicticornis males (Fig. 4).

\section{Heterospecific Couples Vibrational Communication and Behavior}

In heterospecific couples most females of both species $(60 \%, 15 / 25)$ spontaneously emitted FS-1. Males did not show regular responses to these signals: only $43 \%(7 / 15)$ of $C$. impicticornis and $53 \%$ (8/15) of C. ubica males responded with MS-1 signals in duet with heterospecific female FS-1 emission (Fig. 5). These duets lasted for a short time from few seconds to one or two minutes. Fifty percent of $C$. ubica female x C. impicticornis male and $37 \%$ of C. ubica male x C. impicticornis female heterospecific couples showed no further reproductive behavior after the duet phase. Those males that preceded mating behaviour walked in the direction of the females and antennated them. Most of the females rejected copulation although males expressed copulatory position (Fig. 5). No heterospecific copulation was observed.

The proportion of responses to played-back conspecific and heterospecific signals were similar for females and males of each species when stimulated with signals of the other gender (Fig. 6). Odd ratio analyses showed no difference in the proportion of male and female responses to heterospecific signals in relation to conspecific signals (Table 4). The sequence of signals played-back does not show any significant effect on proportions of pulses related to number of pulses in playback signals (beta regression $\mathrm{z}=-1.15 P=0.25$ and $\mathrm{z}=1.11 P=0.27$ for $C$. ubica males responding to FS1a and 


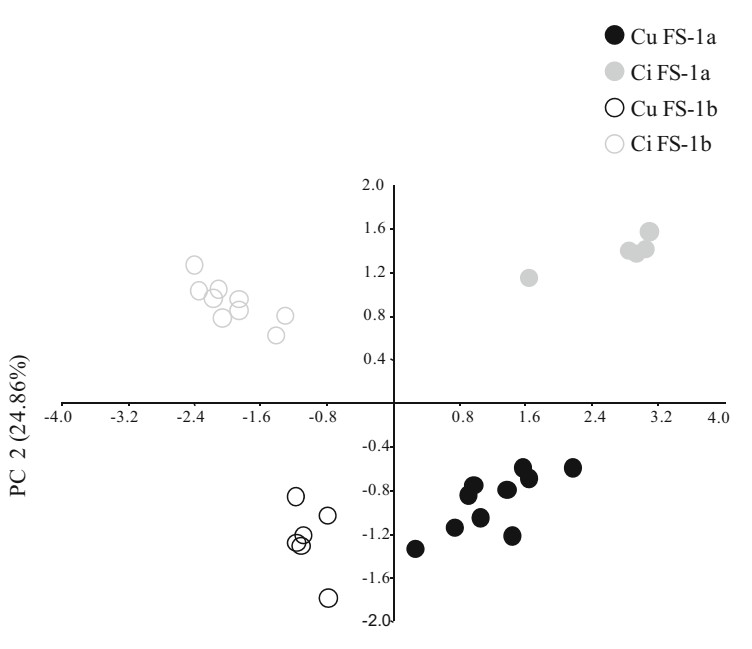

PC $1(66,98 \%)$
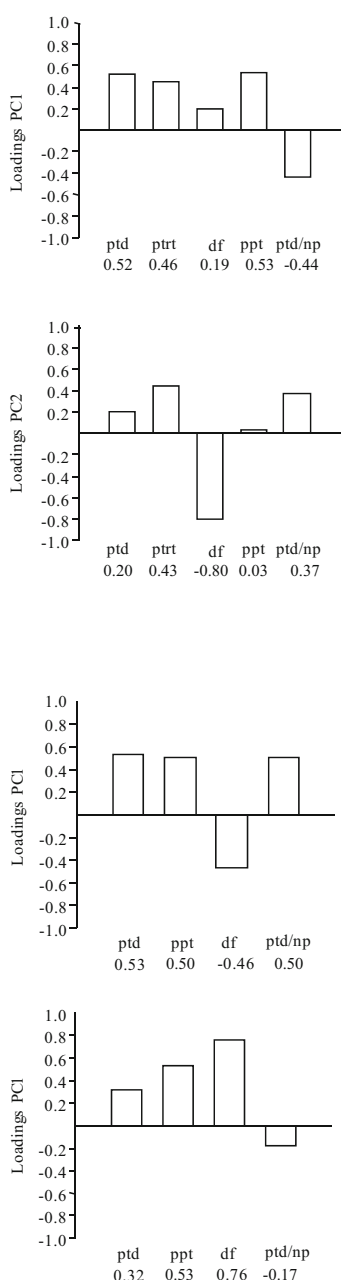

Fig. 4 PCAs for the pulse trains of the female (FS-1a and FS-1b, upper figure) and male (MS-1, lower figure) songs of Chinavia impicticornis (Ci) and Chinavia ubica $(\mathrm{Cu})$. PCAs were performed using the correlation matrix of different variables measured from 5 to 10 individuals of each species/song. Figures at left show the loading of each variable for the first and second component, numbers between brackets show the $\%$ of total variation explained by each component. Ptd: pulse train duration, ptrt: pulse train repetition time, df: dominant frequency of the pulse train, ppt: number of pulses/pulse train

F1b respectively and $\mathrm{z}=0.93 P=0.35$ and $\mathrm{z}=-0.38 P=0.71$ for $C$. impicticornis males responding to FS1a and F1b respectively). In contrast males of both species responded with higher proportions of pulses related to number of pulses in playback signals when conspecific female signals were played-back, with the only exception of C. ubica males when were stimulated with FS1a (beta regression $\mathrm{z}=0.41 P=0.68$ and $\mathrm{z}=3.60 P<0.001$ for $C$. ubica males responding to FS1a and F1b respectively and $\mathrm{z}=-2.89 P=0.004$ and $\mathrm{z}=-2.70 P<0.007$ for $C$. impicticornis males responding to FS1a and F1b respectively) (Fig. 7). 
C. ubica females x C. impicticornis males

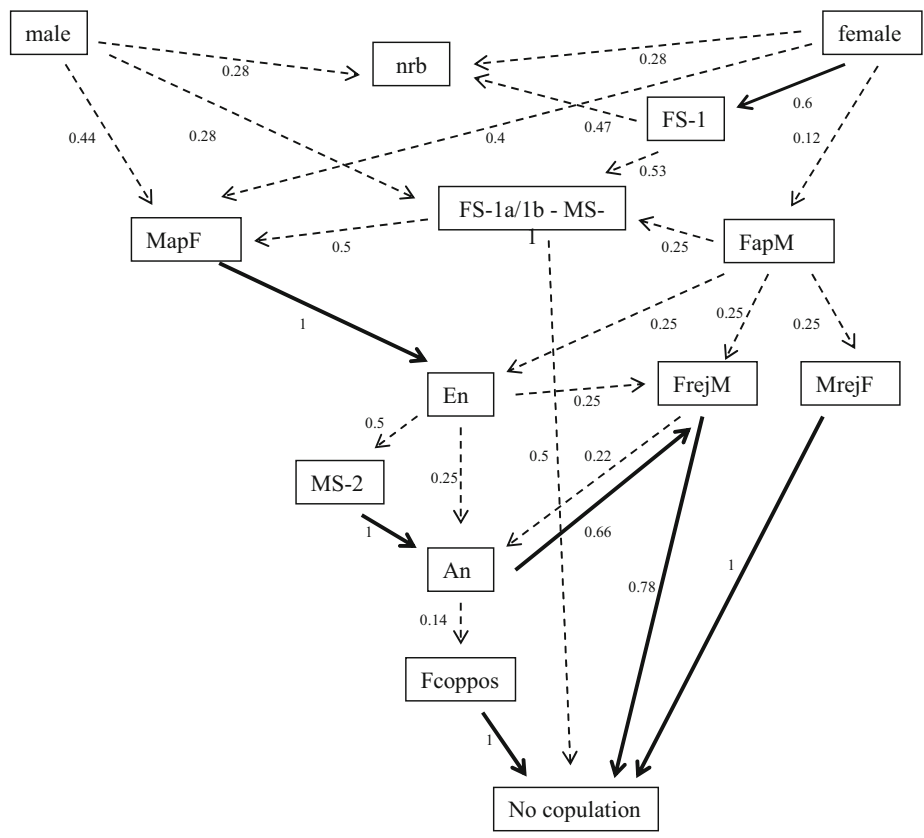

C. ubica males x C. impicticornis females

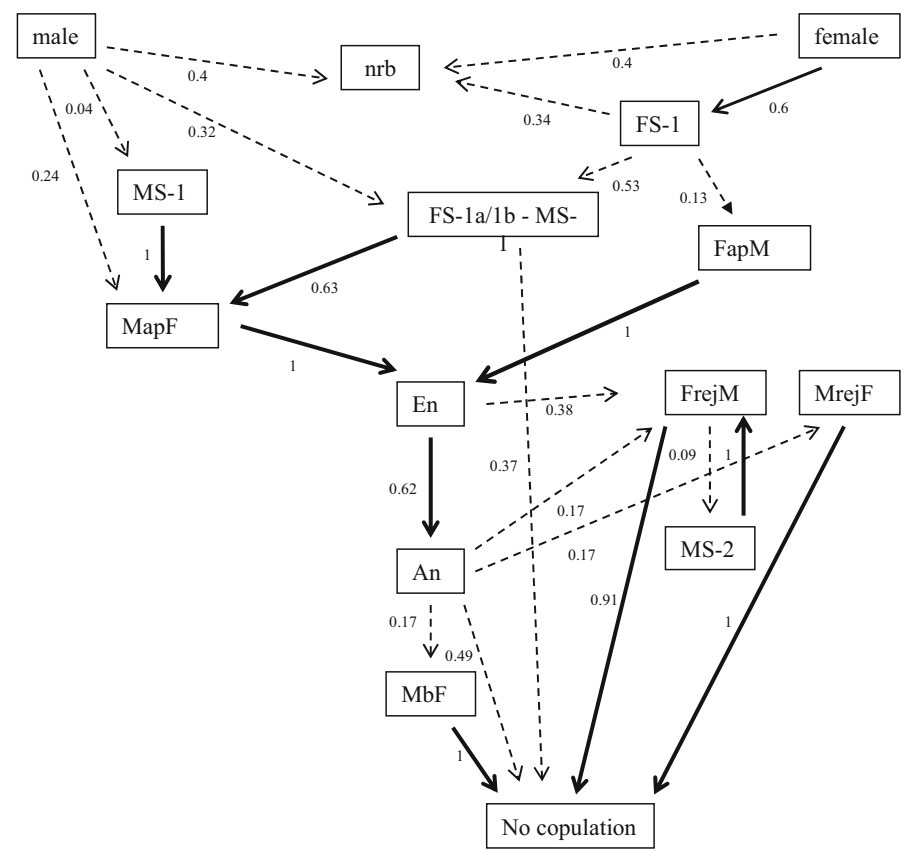


4 Fig. 5 Sequence of courtship and mating behavior of Chinavia impicticornis and Chinavia ubica heterospecific couples. Values at left or below lines represent the probability of transitions between behaviours. Solid-line arrows indicate the significant transitions $(P<0.05)$ and dashed-line arrows the non-significant transitions $(P>0.05)$. Boxes represent behavioural categories. FS-1a $=$ female vibratory signal $1 \mathrm{a}, \mathrm{FS}-1 \mathrm{~b}=$ female vibratory signal $1 \mathrm{~b}$, MS-1 = male vibratory signal 1 , MS-2 = male vibratory signal 2 . Codes for behavioral categories are listed in Table 1

Males

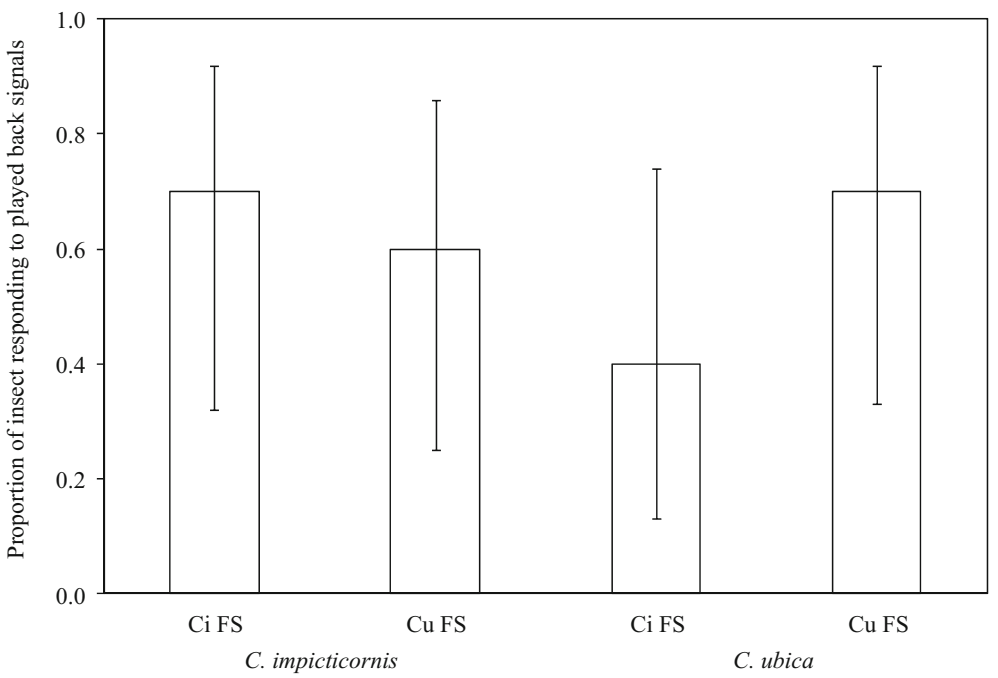

Females

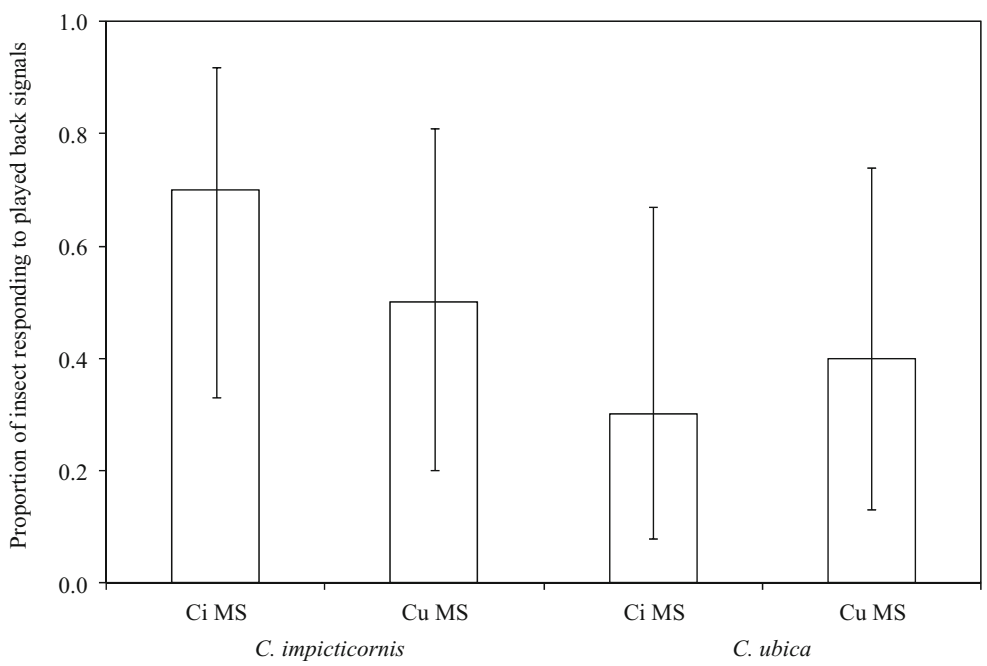

Fig. 6 Mean proportion of responses of male and females of Chinavia impicticornis and Chinavia ubica when stimulated by conspecific and heterospecific songs. Proportion of responses were calculated from back transform estimated parameter from a logistic regression and lines indicates $95 \%$ CI calculated using the estimated parameter and standard deviation from logistic regression 
Table 4 Probability of Chinavia ubica and Chinavia impicticornis females and males responding to heterospecific signals in playback experiments

\begin{tabular}{llll}
\hline Species/sex & Odds ratio & CI $(95 \%)$ & Significance \\
\hline C. ubica females & 0.64 & $0.10-4.10$ & $\mathrm{Z}=0.47 P=0.64$ \\
C. ubica males & 0.28 & $0.04-1.83$ & $\mathrm{Z}=1.33 P=0.18$ \\
C. impicticornis females & 0.43 & $0.07-2.67$ & $\mathrm{Z}=0.91 P=0.37$ \\
C. impicticornis males & 0.64 & $0.10-4.10$ & $\mathrm{Z}=0.47 P=0.64$ \\
\hline
\end{tabular}

\section{Discussion}

Reproductive behavior and vibratory communication showed similar trends in the two Chinavia species studied. The sequence of mating behavioral steps (displays) was highly stereotyped in both species and the repertoire of vibratory communication songs was composed of signals with similar temporal and spectral characteristics. Notwithstanding, some differences observed in temporal and spectral characteristics of female and male signals enable species discrimination in multivariate analyses. Insects that responded to heterospecific vibratory signals did not step forward to behavioral steps

Chinavia impicticornis males
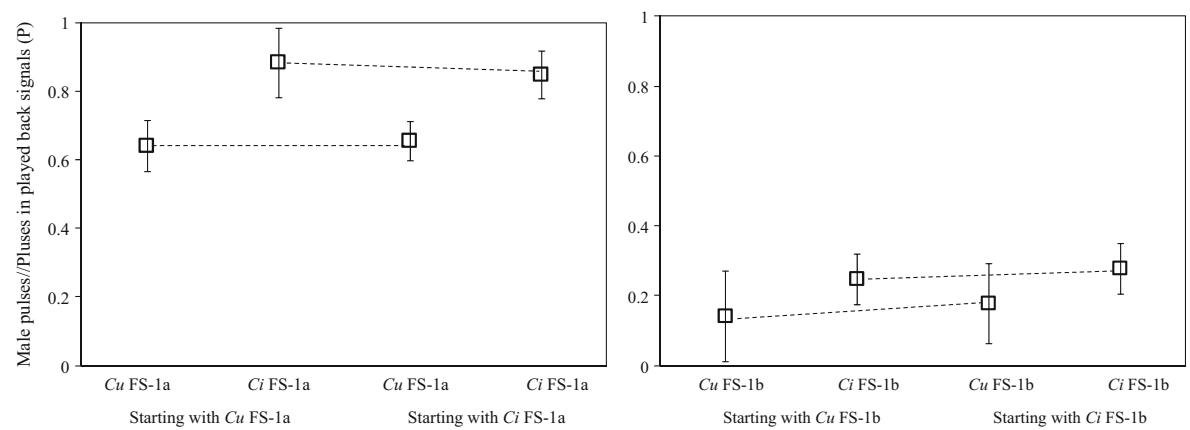

Chinavia ubica males
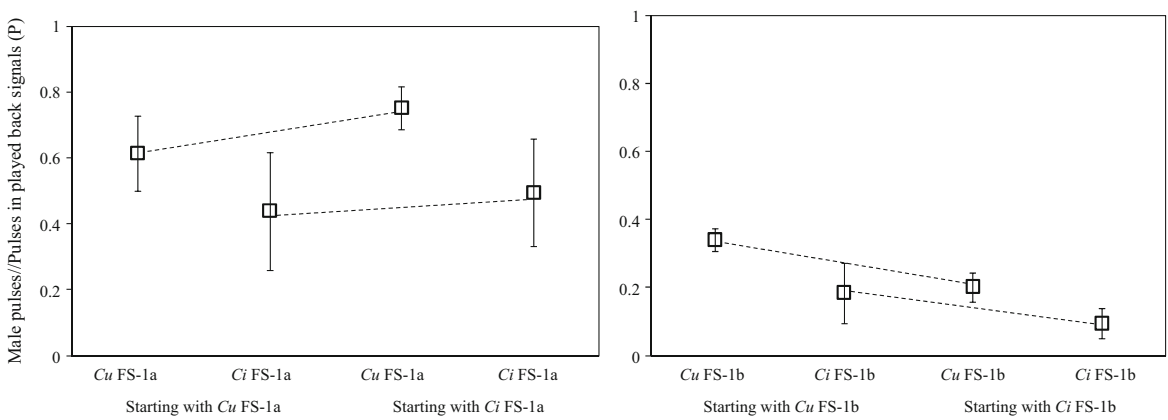

Fig. 7 Ratio of number of pulses of MS of Chinavia impicticornis and Chinavia ubica to number of pulses of played-back signals (FS1a and FS1b) in different sequences. See text for details of statistical tests 
leading to copulation. Interspecific communication remained in all cases at the initial (calling) level and no heterospecific copulations were observed.

The repertoire of signals and their association with specific behaviors of both Chinavia species is similar to those reported for other Pentatomine stink bugs (Čokl and Virant-Doberlet 2003; Čokl 2008; Silva et al. 2012; Blassioli-Moraes et al. 2005, 2014) and the sequence of reproductive displays at close range is also similar to that reported previously for phytophagous and predatory stink bugs (Borges et al. 1987; Kon et al. 1988; Wang and Millar 1997; Zahn et al. 2008; Žunič et al. 2008; Silva et al. 2012; Laumann et al. 2013; Blassioli-Moraes et al. 2014).

C. impicticornis vibratory songs recorded with the laser vibrometer on loudspeaker membrane and on plants have similar characteristics to those analysed and described as FS-1 and FS-2 from records obtained directly from loudspeaker membrane by Blassioli-Moraes et al. (2005). Similar temporal and spectral characteristics of songs in the same behavioral context permit consideration that these signals are two types of the female calling song. FS-1a shows a well-structured pattern of temporal parameters with highly uniform pulses and pulse train duration and stable repetition time as typical for Pentatominae calling songs (Čokl and Virant-Doberlet 2003; Čokl 2008). On the other hand, FS-1b signals show higher variation in their temporal characteristics and are related with male signals in a duet, suggesting transition to courtship displays.

Species specific information based predominantly on temporal and frequency characteristics of $C$. impicticornis and C. ubica vibratory signals has also been shown in many other stink bug species (Blassioli-Moraes et al. 2005; Čokl 2008; de Groot et al. 2010; Žunič et al. 2011), as well as in other insect groups that communicate either with plantborne signals, like planthoppers (Claridge et al. 1985, 1988) and treehoppers (Rodríguez et al. 2004, Rodriguez et al. 2006; Rodríguez and Cocroft 2006) or even in animals that use air bone sounds as bush- crikets (Dobler et al. 1994) and katydids ( Forrest et al. 2006) or vertebrates as the frog Xenopus levis (Daudin, 1802) (Vignal and Kelley 2007).

In particular, for Pentatominae, de Groot et al. (2010) and Žunič et al. (2011) showed that Nezara viridula males recognize and respond to the female calling song based principally on pulse train duration and interval. Calling songs of $N$. viridula populations from different geographical origins (continents) have different time characteristics (Čokl et al. 2000; Miklas et al. 2003) and males respond preferentially to female songs of their own population (Miklas et al. 2003). Results of heterospecific duetting in C. impicticornis and C. ubica suggest that time parameters could be the responsible for the interruption of the initially started vibrational communication and prevents female male duetting, a prerequisite for successful copulation.

Although frequency characteristics of vibratory signals show differences between Chinavia species they are in the range of until now investigated pentatomine stink bugs, dominant frequencies around $100 \mathrm{~Hz}$ (Čokl et al. 2014). However, stink bugs show some variability of frequency characteristics as observed in signals from different geographically isolated populations (Čokl et al. 2000), in signals with different frequency modulation (McBrien and Millar 2003; Blassioli-Moraes et al. 2005) or frequency sweeps produced as response to environmental (Polajnar and Čokl 2008) or to biotic noise (Čokl et al. 2015). Frequency differences of female calling song signals in a broad range around the dominant frequency did not modulate significantly male responses in N. viridula (Žunič et al. 2011). Detailed playback experiments with signals of different time and frequency characteristics are needed in Chinavia species to determine their relevance in song recognition. 
The stink bugs' vibratory signal repertoire shows similar components (calling, courtship and rivalry signals), with variation between species related to signal temporal and spectral compositions (Blassioli-Moraes et al. 2005; Čokl and Virant-Doberlet 2003; Laumann et al. 2013; Shestakov 2015). This suggests that from a basic signal species specific characteristics could be acquired by gradual changes in signal structure. The same pattern has been described in other insects as, for example, treehoppers (Cocroft et al. 2010), planthoppers (Den Bieman 1986) and crickets (Mendelson and Shaw 2002). These changes in signal systems could be related to biases in the signal emission, in the sensory and cognitive system or even in the behavior associated with the signalling (Endler 1993).

We can conclude that heterospecific mating between investigated Chinavia species stops at an earlier stage compared with sympatric $N$. viridula and $N$. antennata (Kon et al. 1988, 1993, 1994). Despite very different vibratory communication signals in the two Nezara species, the authors found inter-specific copulation, and this phenomenon was related to the straight range of sympatric distribution of the two Nezara species. Kon et al. (1988) stated that this could happen because in allopatric species sexual selection could lead to fast divergence of sexual signals independently of species recognition systems, a fact also observed in allopatric populations of the planthooper Nilaparvata bakeri (Muir) (Claridge and Morgan 1993). For the Chinavia species studied here, that are sympatric in almost their geographic distribution (Panizzi et al. 2000; Schwertner and Grazia 2007), differences on signals parameters efficiently prevent hybridization. It will be interesting in the future to study the signals and behavioral characteristics of allopatric populations, found in northern and southern limits of geographic distribution (Schwertner and Grazia 2007), of these species to have a complete picture about signals evolution and species recognition systems in stink bugs.

The prezygotic isolation observed in very close Chinavia species appear to be based on specificity of pheromone blends (Blassioli-Moraes et al. 2012) and vibratory signals (data presented here) and agree with the hypotheses of phenotypic architecture influence on behavioral reproductive isolation (Mendelson and Shaw 2012). As the ultimate consequence of signals differences is preventing hybridization and gene flow between species, sexual communication could have a central role in speciation (West-Eberhard 1983; Mendelson and Shaw 2012). To test this hypothesis in stink bugs a more detailed study including several species, their known phylogeny and their repertory of signals need to be conducted in the future.

For a full knowledge of the function of species-specific courtship and mating signals and their contribution to communication through a private intraspecific channel one needs to relate the structure and characteristics of signals with the mate preferences (Ritchie 1996, 2007; Ritchie et al. 1999; Mendelson and Shaw 2012). In this way, further experiments are needed to identify and evaluate the decisive role of duration and/or repetition time of signals pulse and pulse train characteristics in discrimination and preferences of conspecific signals by the sympatric Chinavia species.

Acknowledgments The authors are grateful to Samantha da Silveira for technical support with insect rearing and playback experiments and colleague from The National Institute of Biology in Ljubljana and from the Semiochemical Laboratory, EMBRAPA Genetic Resources and Biotechnology in Brasilia for fruitful discussion with comments on the manuscript. We also thank two anonymous reviewers for their useful comments that help to improve first version of the manuscript. This work received financial support from Slovenian Research Agency, program number: P1-0255, project number: BI-BR/12-12/002 and CNPqMHNEST 40245/2011-0. FAP-DF project 193.000.023-2012 and Embrapa. 


\section{References}

Aldrich JR (1988) Chemical ecology of the Heteroptera. Annu Rev Entomol 33:211-238

Aldrich JR, Oliver JE, Lusby WR, Kochhar TS, Lockwood JA (1987) Pheromone strains of the cosmopolitan pest, Nezara viridula (Heteroptera: Pentatomidae). J Exp Zool 244:171-175

Baker R, Borges M, Cooke NG, Herbert RH (1987) Identification and synthesis of (Z)-(1'S,3'R,4'S)(-)-2-(3',4'epoxy-4'-methylcyclohexyl)-6-methylhepta-2,5-diene, the sex pheromone of the southern green stink bug, Nezara viridula (L.). J Chem Soc Chem Commun 6:414-416

Blassioli-Moraes MCB, Laumann RA, Čokl A, Borges M (2005) Vibratory signals of four Neotropical stink bug species. Physiol Entomol 30:175-188

Blassioli-Moraes MCB, Pareja M, Laumann RA, Borges, M (2008) The chemical volatiles (Semiochemicals) produced by neotropical stink bugs (Hemiptera: Pentatomidae) Neotrop Entomol 37:489-505

Blassioli-Moraes MC, Laumann RA, Oliveira MWM, Woodcock CM, Mayon P, Hooper A, Pickett JA, Birkett MA, Borges M (2012) Sex pheromone communication in two sympatric Neotropical stink bug species Chinavia ubica and Chinavia impicticornis. J Chem Ecol 38:836-845

Blassioli-Moraes MC, Magalhães DM, Čokl A, Laumann RA, Silva JP, Cleonor Silva CCA, Borges M (2014) Vibrational communication and mating behavior of Dichelops melacanthus (Hemiptera: Pentatomidae) recorded from loudspeaker membranes and plants. Physiol Entomol 39:1-11

Borges M, Jepson P, Howse P (1987) Long-range mate location and close-range courtship behaviour of the green stink bug, Nezara viridula and its mediation by sex pheromones. Entomol Exp Appl 44:205-212

Broughton WB (1963) Methods in bio-acoustic terminology. In: Busnel RG (ed) Acoustic Behaviour of Animals.: Elsevier Publishing Company, Amsterdam-London-New York, pp 3-24

Claridge MF, Morgan JC (1993) Geographical variation in acoustic signals of the planthopper, Nilaparvata bakeri (Muir), in Asia: species recognition and sexual selection. Biol J Linn Soc 48:267-281

Claridge MF, Den Hollander J, Morgan JC (1985) The status of weed-associated populations of the brown planthopper, Nilaparuata lugens (Stål)-host race or biological species? Zool J Linnean Soc 84:77-90

Claridge MF, Den Hollander J, Morgan JC (1988) Variation in host plant relations and courtship signals of weed-associated populations of the brown planthopper, Nilaparuata lugens (Stål), from Australia and Asia: a test of the recognition species concept. Biol J Linn Soc 35:79-93

Cocroft RB, Rodrígues RL (2005) The behavioural ecology of insect vibrational communication. Biosci 55: 323-334

Cocroft RB, Rodríguez RL, Hunt RE (2010) Host shifts and signal divergence: mating signals covary with host use in a complex of specialized plant-feeding insects. Biol J Linn Soc 99:60-72

Čokl A (2008) Stink bug interaction with host plants during communication. J Insect Physiol 54:1113-1124

Čokl A, Virant-Doberlet M (2003) Communication with substrate-borne signals in small plant-dwelling insects. Annu Rev Entomol 48:29-50

Čokl A, Virant Doberlet M, Stritih N (2000) The structure and function of songs emitted by southern green stink bugs from Brazil, Florida, Italy and Slovenia. Physiol Entomol 25:1-10

Čokl A, McBrien H, Millar JG (2001) Comparison of substrate-borne vibrational signals of two stink bugs species, Acrosternum hilare and Nezara viridula (Heteroptera: Pentatomidae). Ann Entomol Soc Am 94: $71-479$

Čokl A, Zorović M, Žunič Kosi A, Stritih N, Virant-Doberlet M (2014) Communication through plants in a narrow frequency window. In: Cocroft RB, Gogala M, hill PSM, Wessel a, (eds)studying vibrational communication. Springer, Heidelberg, New York, Dordercht, London, pp. 171-189

Čokl A, Laumann RA, Žunič Kosi A, Blassioli-Moraes MC, Virant-Doberlet M, Borges M (2015) Interference of overlapping insect vibratory communication signals: an Eushistus heros model. PLoS One 10(6):e0130775. doi:10.1371/journal.pone.0130775

de Groot M, Čokl A, Virant-Doberlet M (2010) Effects of heterospecific and conspecific vibrational signal overlap and signal-to-noise ratio on male responsiveness in Nezara viridula (L.). J Exp Biol 213:32133222

Den Bieman CFM (1986) Acoustic differentiation and variation in planthoppers of the genus Ribautodelphax (Homoptera, Delphacidae). Neth J Zool 36:461-480

Dobler S, Stumpner A, Heller KG (1994) Sex-specific spectral tuning for the partner's song in the duetting bush-cricket Ancistrura nigrovittata (Orthoptera: Phaneropteridae). J Com Physiol A 175:303-310

Endler JA (1993) Some general comments on the evolution and design of animal communication systems. Philos Trans R Soc Lond Ser B Biol Sci 340:215-225

Fehr WR, Caviness CE, Burmood DT, Pennington JS (1971) Stage of development descriptions for soybeans, Glycine max (L.) Merrill. Crop Sci 11:929-931 
Forrest TG, Lajoie DR, Cusick D (2006) Calling songs, duets, and auditory tuning in two cryptic katydids (Tettigoniidae: Phaneropterinae: Amblycorypha). Ann Entomol Soc Am 99:978-987

Greenfield MD (2002) Signals and receivers. Mechanism and evolution of arthropod communication. Oxford University Press, New York

Gröning J, Hochkirch A (2008) Reproductive interference between animal species. Q Rev Biol 83:257-282

Haccou P, Meelis E (1992) Statistical analysis of behavioural data: an approach based on time-structured models. Oxford University Press, Oxford

Hammer O, Harper DAT, Ryan PD (2001) PAST: paleontological statistics software package for education and data analysis. Pal Elect 4:1-9 Available at http://palaeo-electronica.org/2001_1/past/issue1_01.htm

Harris VE, Todd JW (1980) Temporal and numerical patterns of reproductive behavior in the southern green stink bug, Nezara viridula (Hemiptera: Pentatomidae). Entomol Exp Appl 27:105-116

Higuchi H (1992) Population prevalence of occurrence and spatial distribution pattern of Piezodorus hybneri adults (Heteroptera: Pentatomidae) on soybeans. Appl Entomol Zool 27:363-369

Kirkpatrick M, Ravigne V (2002) Speciation by natural and sexual selection: models and experiments. Am Nat 159:S22-S35

Kon M, Oe A, Numata H, Hidaka T (1988) Comparison of the mating behaviour between two sympatric species, Nezara viridula and $N$. antennata (Heteroptera: Pentatomidae), with special reference to sound emission. J Ethol 6:91-98

Kon M, Oe A, Numata H (1993) Intra- and interspecific copulations in the two congeneric green stink bugs, Nezara antennata and $N$. viridula (Heteroptera, Pentatomidae), with reference to postcopulatory changes in the spermatheca. J Ethol 11:83-89

Kon M, Oe A, Numata H (1994) Ethological isolation between two congeneric green stink bugs, Nezara antennata and N. viridula (Heteroptera, Pentatomidae). J Ethol 12:67-71

Laumann RA, Kavčič A, Moraes MCB, Borges M, Čokl A (2013) Reproductive behaviour and vibratory communication of the neotropical predatory stink bug Podisus nigrispinus. Physiol Entomol 38:71-80

McBrien HL, Millar JG (2003) Substrate-borne vibrational signalling in the consperse stink bug, Euschistus conspersus. Can Entomol 135:555-567

McBrien HL, Millar JG, Gottlieb L, Chen X, Rice RE (2001) Male-produced sex attractant pheromone of the green stink bug, Acrosternum hilare (say). J Chem Ecol 27:1821-1839

Mendelson TC, Shaw KL (2002) Genetic and behavioural components of the cryptic species boundary between Laupala cerasina and L. kohalensis (Orthoptera: Gryllidae). Genet 116:301-310

Mendelson TC, Shaw KL (2012) The (mis) conception of species recognition. Trends Ecol Evol 27:421-427

Miklas N, Čokl A, Renou M, Virant-Doberlet M (2003) Variability of vibratory signals and mate choice selectivity in the southern green stink bug. Behav Process 61:131-142

Panizzi AR, McPherson JE, James DG, Javahery M, McPherson RM (2000) Economic importance of stink bugs (Pentatomidae). In: Schaefer CW, Panizzi AR (eds) Heteroptera of economic importance. CRC Press, Boca Raton, Florida, pp. 421-474

Polajnar J, Čokl A (2008) The effect of vibratory disturbance on sexual behaviour of the southern green stink bug Nezara viridula (Heteroptera, Pentatomidae). Cen Eur J Biol 3:189-197

Ritchie MG (1996) The shape of female mating preferences. Proc Natl Acad Sci U S A 93:14628-14631

Ritchie MG (2007) Sexual selection and speciation. Annu Rev Ecol Evol Syst 38:79-102

Ritchie MG, Halsey EJ, Gleason JM (1999) Drosophila Song as a species-specific mating signal and the behavioural importance of Kyriacou \& Hall cycles in D. melanogaster Song. Anim Behav 58:649-657

Rodríguez RL, Cocroft RB (2006) Divergence in female duetting signals in the Enchenopa binotata species complex of treehoppers (Hemiptera: Membracidae). Ethol 112:1231-1238

Rodríguez RL, Sullivan LE, Cocroft RB (2004) Vibrational communication and reproductive isolation in the Enchenopa binotata species complex of treehoppers (Hemiptera: Membracidae). Evol 58:571-578

Rodriguez RL, Ramaswamy K, Cocroft RB (2006) Evidence that female preferences have shaped male signal evolution in a clade of specialized plant-feeding insects. Proc R Soc B Biol Sci 273:2585-2593

Roggia RCRK (2009) Spatial and temporal distribution of soybean stink bug and behaviour of Piezodorus guildinii (Westwood, 1837) (Hemiptera: Pentatomidae) on soybean (Glycine max (L.) on day time. Doctoral Thesis, Universidade Federal de Santa Maria

Ryan RJ, Rand AS (1993) Species recognition and sexual selection as a unitary problem in animal communication. Evol 47:647-657

Schwertner CF, Grazia JO (2007) O gênero Chinavia Orian (Hemiptera, Pentatomidae, Pentatominae) no Brasil, com chave pictórica para os adultos. Rev Bras Entomol 51:416-435

Scott-Philips TC (2008) Defining biological communication. J Evol Biol 21:387-395

Seyfarth RM, Cheney DL, Bergman T, Fischer J, Zuberbühler K, Hammerschmidt K (2010) The central importance of information in studies of animal communication. Anim Behav 80:3-8 
Shestakov LS (2015) A comparative analysis of vibrational signals in 16 sympatric species (Pentatomidae, Heteroptera). Entomol Rev 95:310-325

Silva CCA, Laumann RA, Ferreira JBC, Blassioli-Moraes MC, Borges M, Čokl A (2012) Reproductive Biology, mating Behavior, and Vibratory Communication of the Brown-winged Stink Bug, Edessa meditabunda (Fabr.) (Heteroptera: Pentatomidae). Psyche 2012: 1-9. doi:nnn10.1155/2012/598086

Silva CC, Laumann RA, Blassioli-Moraes MC, Aquino MFS, Borges M (2015) Comparative biology of two congeneric stinkbugs, Chinavia impicticornis and C. ubica (Hemiptera: Pentatomidae) Pesq Agropec Bras 50:355-362

Tillman PG, Northfield TD, Mizell RF, Riddle TC (2009) Spatiotemporal patterns and dispersal of stink bugs (Heteroptera: Pentatomidae) in peanut-cotton farmscapes. Environ Entomol 38:1038-1052

Vignal C, Kelley D (2007) Significance of temporal and spectral acoustic cues for sexual recognition in Xenopus laevis. Proc R Soc B Biol Sci 274:479-488

Wang Q, Millar JG (1997) Reproductive behavior of Thyanta pallidovirens (Heteroptera: Pentatomidae). Ann Entomol Soc Am 90:380-388

West-Eberhard MJ (1983) Sexual selection, social competition, and speciation. Q Rev Biol 58:155-183

Zahn DK, Girling RD, McElfresh JS, Cardé RT, Millar JG (2008) Biology and reproductive behavior of Murgantia histrionica (Heteroptera: Pentatomidae). Ann Entomol Soc Am 101:215-228

Žunič A, Čokl A, Virant-Doberlet M, Millar J (2008) Communication with signals produced by abdominal vibration, tremulation and percussion in Podisus maculiventris (Heteroptera: Pentatomidae). Ann Entomol Soc Am 101:1169-1178

Žunič A, Virant-Doberlet M, Čokl A (2011) Species recognition during substrate-borne communication in Nezara viridula (L.) (Pentatomidae: Heteroptera). J Insect Behav 24:468-487 